\title{
Homograft durability after correction of pulmonary atresia and ventricular septal defect with or without systemic pulmonary collateral arteries
}

Pieter C. van de Woestijne, MD, ${ }^{a}$ Jamie L. R. Romeo, MD, PHD, ${ }^{\mathrm{a}}$ Ingrid van Beynum, MD, PhD, ${ }^{\mathrm{b}}$ Maarten Witsenburg, MD, PhD, ${ }^{\mathrm{c}}$ M. Mostafa Mokhles, MD, PhD, ${ }^{a}$ and Ad J. J. C. Bogers, MD, PhD

\section{ABSTRACT}

Background: Pulmonary atresia and ventricular septal defect (PA-VSD), with or without systemic pulmonary collateral arteries (SPCAs), represents a complex anatomic and surgical spectrum of congenital heart disease. Currently, there is limited evidence on homograft durability after complete correction, which potentially could be affected by anatomic differences in pulmonary vasculature.

Methods: This retrospective single-center study included all 69 consecutive PAVSD patients (46 with SPCAs, 23 without SPCAs) operated on between 1978 and 2018. The primary interest was in homograft durability after complete repair. Longitudinal echocardiographic homograft function and right ventricular systolic pressure were analyzed with linear mixed-effects models.

Results: The median duration of follow-up was 20 years. Of the 46 patients with SPCAs, $37(80.4 \%)$ underwent biventricular correction at a median age of 2.7 years (interquartile range [IQR], 1.8-6.3 years). Two patients are currently awaiting unifocalization and correction. All 23 patients without SPCAs underwent successful complete correction at a median age of 1.6 years (IQR, 1.1-3.6 years). Freedom from any reintervention after 20 years was $15 \%$. When a homograft was used during correction, freedom from homograft replacement after 20 years was comparable in the 2 groups ( $P=.925)$, at $32 \pm 11 \%$ in the SPCA group and $32 \pm 13 \%$ in the non-SPCA group. Indications for homograft replacement were isolated stenosis $(\mathrm{n}=7$; $46.7 \%$ ), isolated regurgitation $(n=3 ; 20.0 \%)$, and mixed stenosis and regurgitation $(n=5 ; 33.3 \%)$ in the SPCA group and isolated stenosis $(n=8 ; 88.9 \%)$ and stenosis and regurgitation $(n=1 ; 11.1 \%$ ) in the non-SPCA group. Peak homograft gradient was significantly $(P=.0003)$ higher in patients without SPCA, with a comparable rate of progression in the 2 groups. However, the prevalence of severe pulmonary regurgitation (PR) was higher in patients with SPCAs, estimated at $35 \%$ at 10 years, compared with $15 \%$ in patients without SPCAs.

Conclusions: Homografts used for right ventricular outflow tract reconstruction in patients with PA-VSD, either with or without SPCAs, have similar limited durability. Repeated reintervention is common, and careful follow-up with attention to severe PR is warranted. (JTCVS Open 2021;8:546-55)

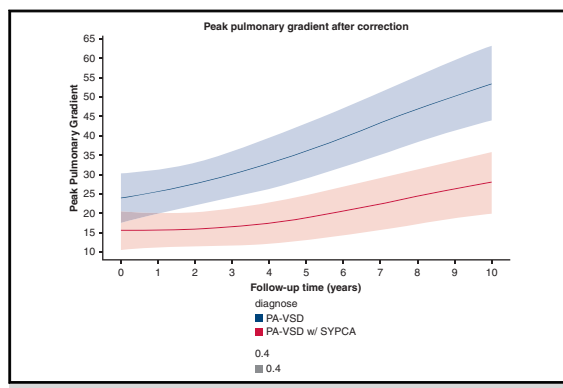

Peak pulmonary gradient in homograft recipients.

CENTRAL MESSAGE

Homografts used for right ventricular outflow tract recon-

struction in patients with

pulmonary atresia and ventricu-

lar septal defect have limited

durability. Reintervention is

common, and follow-up with

attention to pulmonary regurgi-

tation is warranted.

\section{PERSPECTIVE}

Our study with a long follow-up on homograft durability in patients with correction of pulmonary atresia and ventricular septal defect with or without systemic-to-pulmonary collateral arteries (SPCAs) demonstrates that repeated reintervention is common. Longitudinal echocardiographic follow-up showed both stenosis (more in the non-SPCA group) and regurgitation (more in the SPCA group). Careful follow-up is therefore warranted.

See Commentary on page 556.
From the Departments of ${ }^{\text {a }}$ Cardiothoracic Surgery, ${ }^{\mathrm{b}}$ Pediatric Cardiology, and ${ }^{c}$ Cardiology, Erasmus University Medical Centre, Rotterdam, The Netherlands. Dr Mokhles is funded by an NWO Veni grant from the Dutch Organisation for Scientific Research (NWO 916.160.87).

Received for publication March 26, 2021; accepted for publication Sept 17, 2021; available ahead of print Oct 30, 2021.
Address for reprints: Pieter C. van de Woestijne, MD, 's Gravendijkwal 230, 3015 CE Rotterdam, The Netherlands (E-mail: p.vandewoestijne@erasmusmc.nl). 2666-2736

Copyright (C) 2021 The Author(s). Published by Elsevier Inc. on behalf of The American Association for Thoracic Surgery. This is an open access article under the CC BY license (http://creativecommons.org/licenses/by/4.0/). https://doi.org/10.1016/j.xjon.2021.09.025 


\section{Abbreviations and Acronyms \\ BTS = Blalock-Taussig shunt \\ NPA = native pulmonary artery \\ PA = pulmonary atresia \\ $\mathrm{PR}=$ pulmonary regurgitation \\ PVR = pulmonary valve replacement \\ RVOT $=$ right ventricular outflow tract \\ SPCA = systemic-to-pulmonary collateral artery \\ $\mathrm{VSD}=$ ventricular septal defect}

Pulmonary atresia and ventricular septal defect (PA-VSD) with or without systemic pulmonary collateral arteries (SPCAs) are complex congenital cardiac defects. Without surgical intervention, only $75 \%$ of patients survive the first year of life. ${ }^{1}$

Varying sources of blood supply are present. In PA-VSD, the pulmonary arterial system is essentially normal but initially duct-dependent, and most often a first step in surgical treatment consists of creating an aortopulmonary shunt. ${ }^{2,3}$ In PA-VSD with SPCAs, the pulmonary arterial system varies in each SPCA-supplied bronchopulmonary segment combined with a varying presence of native pulmonary arteries (NPAs), and the choice of a single-stage or staged approach is an issue.

In both entities, surgical approach and timing are important considerations. In PA-VSD without SPCAs, the approach is aimed at preservation and inclusion of the complete NPAs. This is also the aim in PA-VSD with SPCAs, but unifocalization and rehabilitation of the pulmonary arterial system are necessary. ${ }^{4,5}$ Regardless of the surgical approach, right ventricular outflow tract (RVOT) reconstruction with a valved conduit, often a homograft, is an essential part of biventricular correction. Because patients with incorporated SPCA segments may be expected to have a less compliant pulmonary arterial bed with higher pulmonary artery pressures owing to suture lines and increased pulmonary vascular resistance, homograft durability might be hampered. Homograft durability may be limited, manifesting as severe stenosis, regurgitation, or a combination of both and is associated with reintervention, morbidity, and mortality.,7 Consequently, in the present study, we aimed to determine homograft durability over our 26-year experience with staged surgical repair of PA-VSD with and without SPCAs.

\section{METHODS}

All consecutive patients with PA-VSD with or without SPCAs who underwent correction between 1978 and 2018 at Erasmus University Medical Center were included. Hospital records were reviewed retrospectively after the Medical Ethics Commission reviewed and approved this study (MEC 12-477, approved 7/1/2012). The requirement for individual informed consent was waived.

\section{Surgical Technique}

All patients were discussed in multidisciplinary meetings involving congenital cardiologists, cardiac surgeons, and radiologists. Eligibility for biventricular complete repair was based on anatomic feasibility and invasive evaluation. In most cases, intracardiac anatomy was determined based on a combination of echocardiography, angiography, and computed tomography scans. The Nakata index was calculated for most patients before and after correction. ${ }^{8}$ The right ventricular systolic pressure was obtained through cardiac catheterization or calculated using the simplified Bernoulli equation based on the systolic tricuspid regurgitation jet. A Nakata index of at least 150 was considered favorable for a positive outcome after complete repair but was not used as an exclusion criterion.

Complete single-stage repair with concomitant unifocalization without the use of homografts was performed in a minority of patients $(n=4$; $8.5 \%$ ) operated on between 1978 and 1992. Since then (1992-2018 and the present day), surgical policy has been a staged approach with RVOT reconstruction using a homograft conduit during final repair as early as clinically feasible. Through separate lateral thoracotomies, unifocalization is intended, with intrapulmonary anastomosis if possible to avoid inclusion of proximal segments of SPCAs in the reconstructed pulmonary vascular bed. In our cohort, these procedures were most often $(n=28)$ completed with an ipsilateral modified Blalock-Taussig shunt (BTS). In cases of a ductal-dependent PA-VSD without SPCAs, neonatal palliation with a modified BTS was applied in all patients, followed later by complete repair.

Correction involved patch closure of the VSD baffling the left ventricle to the aorta and reconstruction of the RVOT with a cryopreserved homograft. No intraoperative flow studies were carried out, and no VSD was deliberately left open. In all cases, intraoperative echocardiography was used to check the adequacy of repair. Primary outcomes were homograft reintervention and replacement.

\section{Statistical Analysis}

Categorical variables are presented as frequency with percentage, and continuous variables are presented as mean with standard deviation or median with range, as appropriate. Time-dependent outcomes are reported using a life tables method for defined periods. Kaplan-Meier plots were created to visualize the occurrence of time-dependent outcomes, and between-group comparisons were made using the log-rank test or Tarone-Ware test as appropriate. Serial echocardiographic measurements of the peak transvalvular homograft gradient and regurgitation grade were analyzed using linear mixed-effects models (Table E1). A significance level of 0.05 was used. Statistical analyses were carried out with SPSS version 24.0 (IBM, Armonk, NY.) and R (R Foundation for Statistical Computing, Vienna, Austria).

\section{RESULTS \\ Interstage Results}

Sixty-nine consecutive patients with SPCAs $(\mathrm{n}=46)$ and without SPCAs $(n=23)$ were been referred to our clinic (Table 1). Among the 39 patients who underwent unifocalization, $29(74.4 \%)$ underwent successful correction at a median age of 2.6 years (interquartile range [IQR], 1.85.8 years) (Figure 1 ). Two patients are currently alive and well and awaiting second unifocalization and complete correction, respectively. All 23 patients without SPCAs achieved correction at a median age of 1.6 years (IQR, 1.1-3.6 years). Of the 46 patients with SPCAs referred to our clinic, 37 underwent attempted correction, which was successful in $36(97.3 \%)$. Therefore, a total of 60 patients underwent complete repair at a median age of 2.2 years 
TABLE 1. Baseline patient characteristics

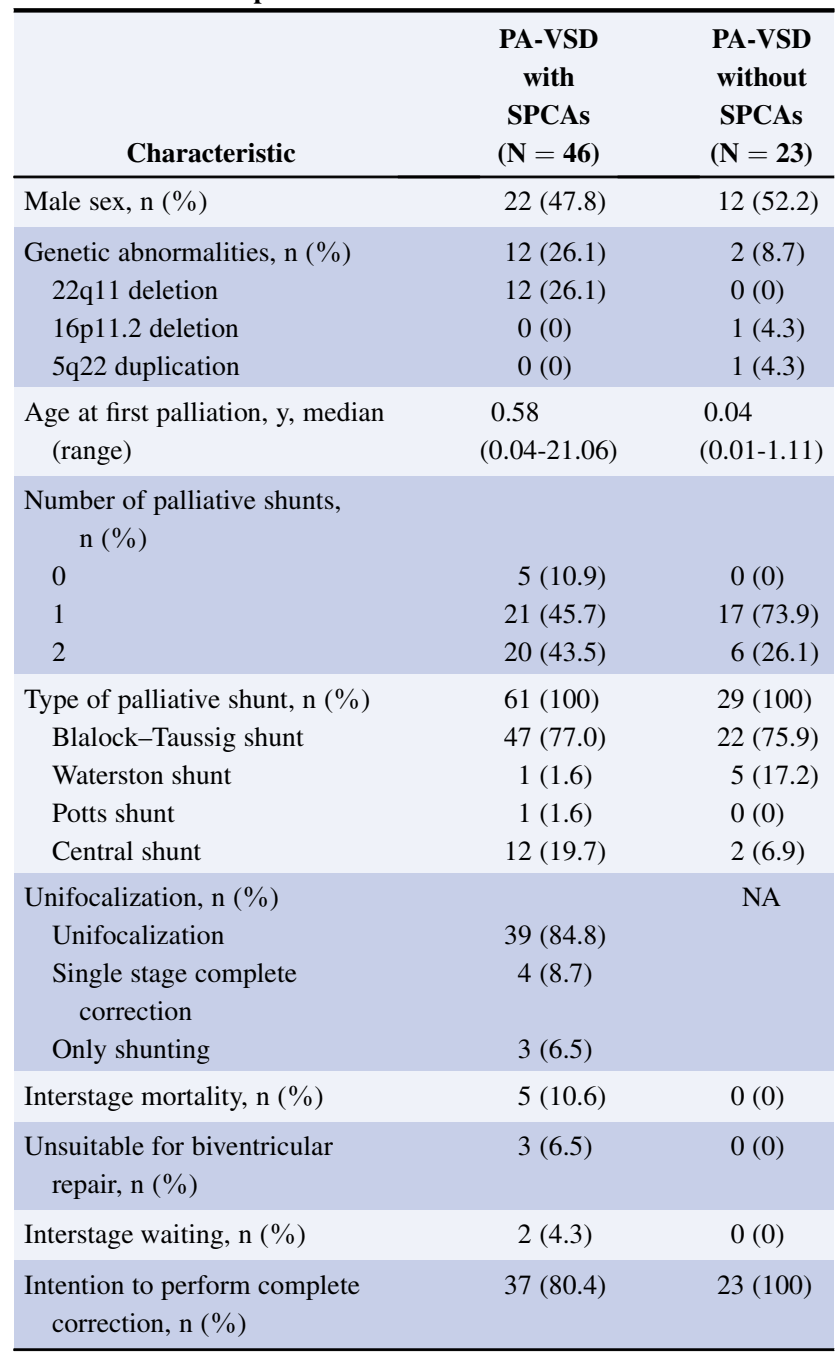

PA-VSD, Pulmonary atresia with ventricular septal defect; SPCAs, systemic pulmonary collateral arteries.

(IQR, 1.3-6.1 years), and surgery was successful in 59 $(98.3 \%$ ) (Table 2). In 54 patients, repair involved the use of a homograft.

\section{Outcome}

Two patients $(5.6 \%)$ from the SPCA group died in the hospital shortly after surgical correction. Follow-up was complete for 56 hospital survivors $(98.2 \%)$ after correction, after a median period of 20.6 years (range, $0.12-38.3$ years) and all within 2 years of study closure. One patient was lost to follow-up immediately after correction owing to emigration to her country of origin. There were 5 late deaths (8.9\%) after a median 3.9 years (range, 0.3-26.1 years) since correction, at a median age of 25.8 years (range 543 years). All 5 late deaths occurred in the SPCA group, including 4 cases of sudden unexplained and unexpected death at 3 months, 5 months, 4 years, and 20 years after correction. The fifth patient died at 26 years after correction from pneumosepsis with right heart failure. Thus, survival at 20 years after correction was $100 \%$ in patients without SPCAs and $86 \pm 6 \%$ in patients with SPCAs (Figure 2).

\section{Hemodynamic Outcomes}

Right ventricular systolic pressure was similar in the 2 groups $(P=.247)$ (Figure 3$)$. The number of patients at risk and measurements available at each year are reported in Table E2. The peak homograft gradient was significantly higher $(P=.0003)$ in patients without SPCA, with a comparable rate of progression in the 2 groups (Figure 4); however, the prevalence of severe pulmonary regurgitation (PR) at 10 years was higher in the patients with SPCAs, estimated at $35 \%$ at 10 years, versus $15 \%$ in those without SPCAs (Figure 5).

Available hemodynamic invasive data in the patients without SPCAs showed low pulmonary artery pressure before correction. In 16 patients, at longer-term (median time since correction, 12 years; range, 2-23 years), the median invasive systolic pulmonary artery pressure was $28 \mathrm{~mm}$ $\mathrm{Hg}$ (range, 14-64 mm Hg), and the median pressure gradient across the homograft was $46 \mathrm{~mm} \mathrm{Hg}$ (range 8-66 $\mathrm{mm} \mathrm{Hg}$ ). Only 2 patients had pulmonary artery branch stenosis with low pressure distally.

Pulmonary artery pressures were significantly higher in the patients with SPCAs. In 18 patients with a median time after correction of 6 years (range, 0-26 years), the median systolic pulmonary artery pressure was $50 \mathrm{~mm} \mathrm{Hg}$ (range, 23-95 $\mathrm{mm} \mathrm{Hg}$ ), and the median pressure gradient across the homograft was only $12 \mathrm{~mm} \mathrm{Hg}$ (range, 0-56 $\mathrm{mm} \mathrm{Hg}$ ).

\section{Late Events: Reintervention}

There were 63 reinterventions on the RVOT in 38 patients $(67.9 \%)$, including 37 surgical interventions and 26 transcatheter interventions after correction (Table 3). Freedom from any intervention in patients with SPCAs was $47 \pm 9 \%$ after 10 years and $23 \pm 9 \%$ after 20 years. In patients without SPCA, these values were $34 \pm 11 \%$ and $9 \pm 7 \%$, respectively. In patients in whom a homograft was inserted as part of correction, freedom from homograft replacement after 20 years was comparable in the 2 groups ( $32 \pm 11 \%$ in the SPCA group and $32 \pm 13 \%$ in the noSPCA group; Tarone-Ware test, $\chi^{2}=0.009 ; P=.925$ ). In the SPCA group, indications for homograft replacement were isolated stenosis in 7 patients $(46.7 \%)$, isolated regurgitation in $3(20.0 \%)$, and mixed stenosis and regurgitation in $5(33.3 \%)$. In the patients without SPCA, isolated stenosis was the indication in 8 patients $(88.9 \%)$, and 1 patient $(11.1 \%)$ had a mixed hemodynamic profile.

All patients who underwent correction without a homograft (ie, a Hancock prosthesis in 2 and transannular patch in 3), received a homograft at a later stage. Surgical 


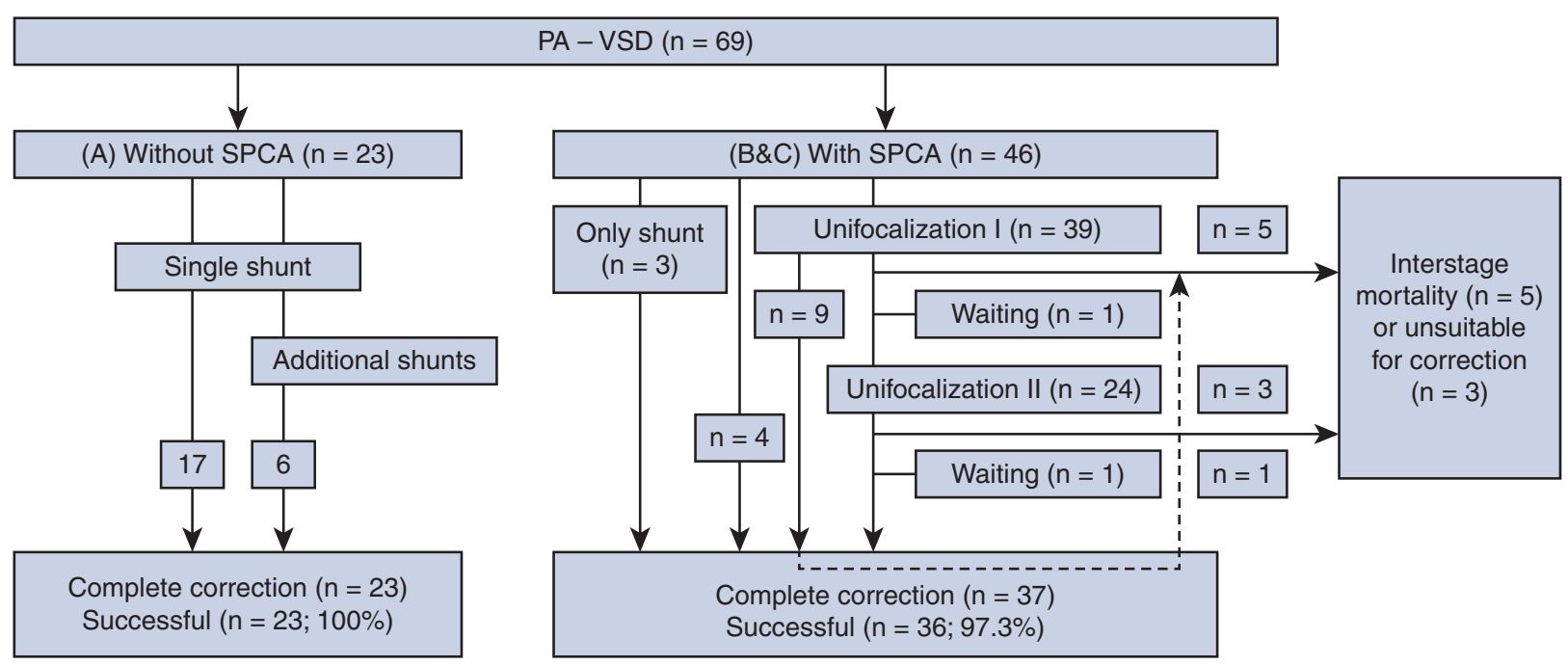

\section{A. Bronchopulmonary segments are only connected to native pulmonary arteries \\ B. Bronchopulmonary segments are connected to both native pulmonary arteries and through SPCA \\ C. Bronchopulmonary segments are only connected through SPCA}

FIGURE 1. Flow chart of the surgical process for all patients. A, Bronchopulmonary segments are connected only to native pulmonary arteries (NPAs). B, Bronchopulmonary segments are connected both through NPAs and through systemic-to-pulmonary collateral arteries (SPCAs). C, Bronchopulmonary segments are connected only through SPCAs. PA-VSD, Pulmonary atresia and ventricular septal defect.

TABLE 2. Baseline characteristics of patients with complete repair

\begin{tabular}{|c|c|c|}
\hline Characteristic & $\begin{array}{c}\text { PA-VSD with } \\
\text { SPCAs } \\
(\mathbf{N}=\mathbf{3 7})\end{array}$ & $\begin{array}{c}\text { PA-VSD } \\
\text { without } \\
\text { SPCAs } \\
(\mathbf{N}=\mathbf{2 3}) \\
\end{array}$ \\
\hline Age, $y$, mean $\pm S D ;$ median (range) & $\begin{array}{c}5.3 \pm 2.7 ; 2.7 \\
(0.08-30.5)\end{array}$ & $\begin{array}{c}2.8 \pm 2.8 \\
1.6(0.4-9.5)\end{array}$ \\
\hline Length, $\mathrm{cm}$, mean $\pm \mathrm{SD}$ & $97 \pm 27$ & $81 \pm 13$ \\
\hline Weight, $\mathrm{kg}$, mean $\pm \mathrm{SD}$ & $15.5 \pm 11.4$ & $10 \pm 3.4$ \\
\hline Creatinine, $\mu \mathrm{mol} / \mathrm{L}$, mean $\pm \mathrm{SD}$ & $34 \pm 15$ & $26 \pm 6.2$ \\
\hline Hemoglobin, mmol/L, median (range) & $10(8-13)$ & $10(8-12)$ \\
\hline Hematocrit, mean $\pm \mathrm{SD}$ & $0.38 \pm 0.47$ & $0.39 \pm 0.50$ \\
\hline $\mathrm{CPB}$ time, min, mean $\pm \mathrm{SD}$ & $186 \pm 70$ & $171 \pm 46$ \\
\hline Cross-clamp time, min, mean $\pm \mathrm{SD}$ & $106 \pm 35$ & $111 \pm 21$ \\
\hline Successful surgery, n (\%) & $36(97.3)$ & $23(100)$ \\
\hline VSD closure, $\mathrm{n}(\%)$ & $36(97.3)$ & $23(100)$ \\
\hline \multicolumn{3}{|l|}{ Valved conduit RVOT reconstruction, $\mathrm{n}(\%)$} \\
\hline Pulmonary homograft & $31(86.1)$ & $16(69.6)$ \\
\hline Aortic homograft & $4(11.1)$ & $3(13.0)$ \\
\hline Transannular patch & $0(0)$ & $4(17.4)$ \\
\hline Other & $1(2.8)$ & $0(0)$ \\
\hline Homograft diameter $(\mathrm{mm})$, median (range)* & $20(12-25)$ & $17(11-24)$ \\
\hline \multicolumn{3}{|l|}{ Postoperative complications, n (\%) } \\
\hline Death & $2(5.6)$ & $0(0)$ \\
\hline Redo thoracotomy & $6(16.7)$ & $1(4.3)$ \\
\hline For bleeding & $4(11.1)$ & $0(0)$ \\
\hline For o & $2(5.6)$ & $1(4.3)$ \\
\hline Other & $4(11.1)$ & $2(8.7)$ \\
\hline
\end{tabular}

$\overline{P A-V S D}$, Pulmonary atresia with ventricular septal defect; SPCAs, systemic pulmonary collateral arteries; $S D$, standard deviation; $C P B$, cardiopulmonary bypass; $R V O T$, right ventricular outflow tract. *If the homograft was bicuspidalized, the final diameter is reported. reintervention due to restenosis of branch pulmonary arteries was performed in 11 patients $(19.6 \%)$. Closure of a residual VSD was performed in 10 patients $(17.9 \%)$. One left-sided modified BTS was reinserted 9 months after correction in a 3-year-old boy owing to restenosis and hypoplasia of the left pulmonary artery with virtually no flow to the left lung. Of the 4 early patients who underwent singlestage unifocalization and correction, 1 patient is still free from reintervention and in good clinical condition 27 years after correction. The other 3 patients underwent reinterventions including pulmonary valve replacement (PVR). One patient who underwent correction at age 6 years died suddenly at age 26 years due to presumed rhythm disturbances. Another female patient who underwent single-stage correction at age 9 years with a Hancock prosthesis underwent PVR with an aortic homograft 11 years later. Seventeen years later, she underwent a Bentall procedure due to severe aortic regurgitation and RVOT reconstruction with a mechanical prosthesis due to severe stenosis and regurgitation of the homograft. She is currently in good clinical condition. The fourth patient underwent complete correction at age 1 month with an aortic homograft, which was replaced 5 years later with concomitant reconstruction of the confluent pulmonary arteries.

\section{DISCUSSION}

Homografts used for RVOT reconstruction in patients with PA-VSD, both with and without SPCAs, have limited durability. Durability is limited primarily by progressive regurgitation in patients with PA-VSD and SPCAs and by progressive stenosis in those with PA-VSD without SPCAs. 

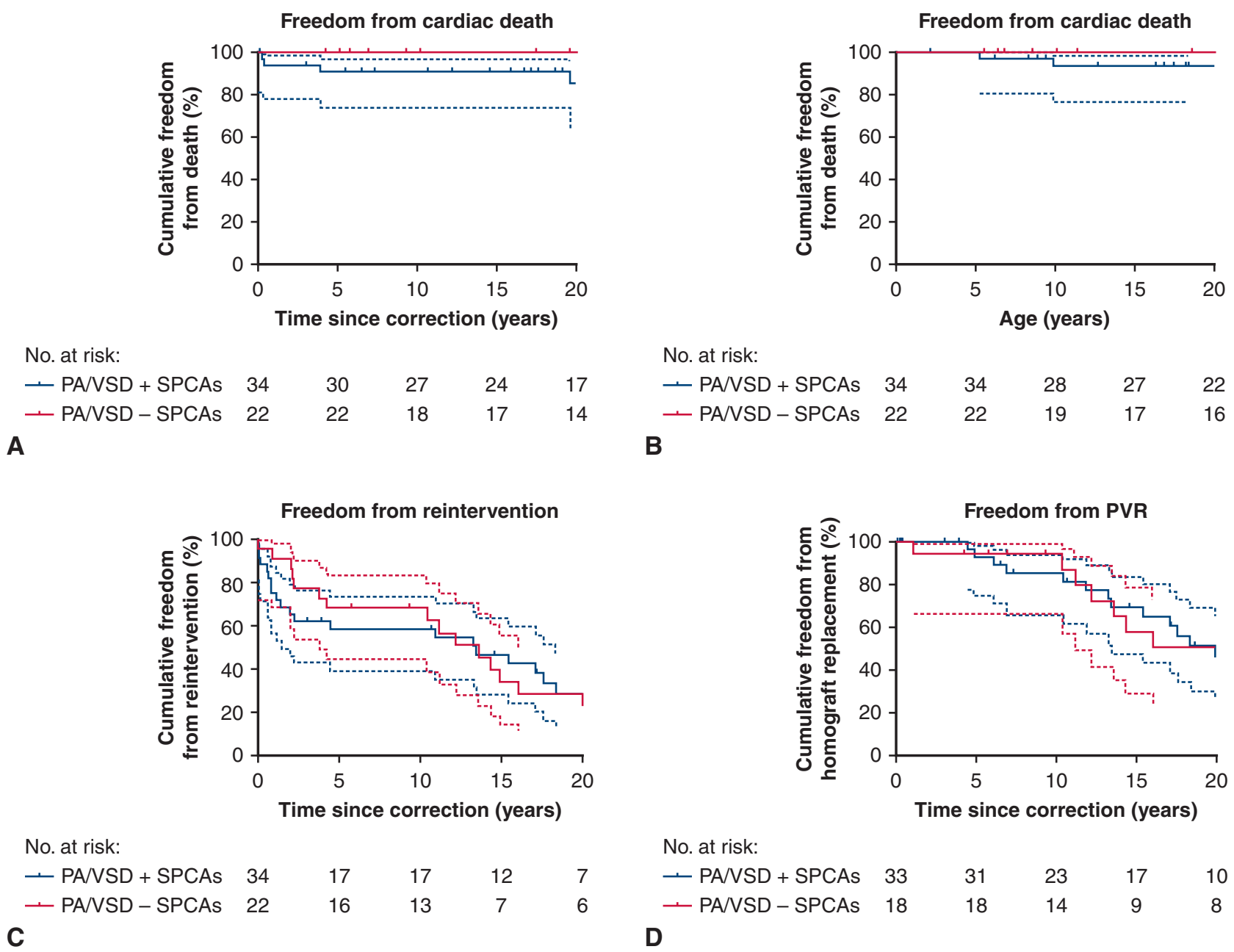

No. at risk:

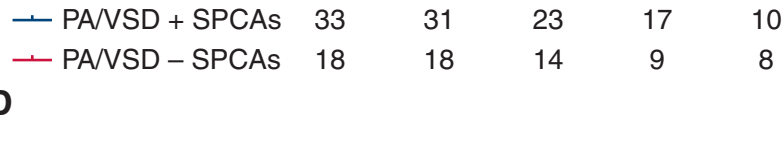

FIGURE 2. A, Kaplan-Meier plot of freedom from death as a function of time since correction, according to diagnosis. B, Kaplan-Meier plot of freedom from death as a function of age, according to diagnosis. C, Kaplan-Meier plot of freedom from first reintervention after complete correction. D, KaplanMeier plot of freedom from pulmonary valve replacement in patients who received an allograft at complete correction. PA/VSD, Pulmonary atresia with ventricular septal defect; SPCAs, systemic pulmonary collateral arteries; PVR, pulmonary valve replacement.

\section{Homograft Durability}

The main shortcoming of homografts is durability, which appears to be especially limited in young patients. ${ }^{9-11}$ It is reasonable to expect most homografts to eventually fail due to severe stenosis, regurgitation, or both. Reports on long-term outcomes after PA-VSD correction emphasizing homograft durability are sparse, but similar high reintervention rates have been reported. ${ }^{12,13}$ In our series, the majority of patients in the SPCA group underwent at least 1 reintervention, and almost one-half of them underwent multiple reinterventions. In both groups, PVR was the most frequently performed surgical reintervention. Increased right ventricular (RV) afterload, which is occasionally present in patients with unifocalized SPCAs, can further limit durability by exerting additional tissue stress. Mainwaring and colleagues ${ }^{13}$ reported a negative correlation between pulmonary artery pressure as directly measured by a catheter postoperatively and aortic homograft durability. Our present results show that both RV systolic pressure and the homograft replacement rate were comparable after correction in our patients with SPCAs and those without SPCAs. Although the peak gradient was significantly higher in the patients without SPCAs, a larger proportion of PVR was indicated by severe PR or mixed stenosis and regurgitation in the patients with SPCAs, which equalized the total PVR rates between the groups. This is remarkably similar to the results presented by Mainwaring and colleagues, in which significant PR was present in the vast majority of failing homografts. ${ }^{13}$ In a swine model, Petit and colleagues ${ }^{14}$ found that a reduction in pulmonary artery pressure can lead to a reduced regurgitation fraction.

The exact nature of the development of high RV systolic pressure over time since correction remains both a question and problem. Our results based on a staged approach 


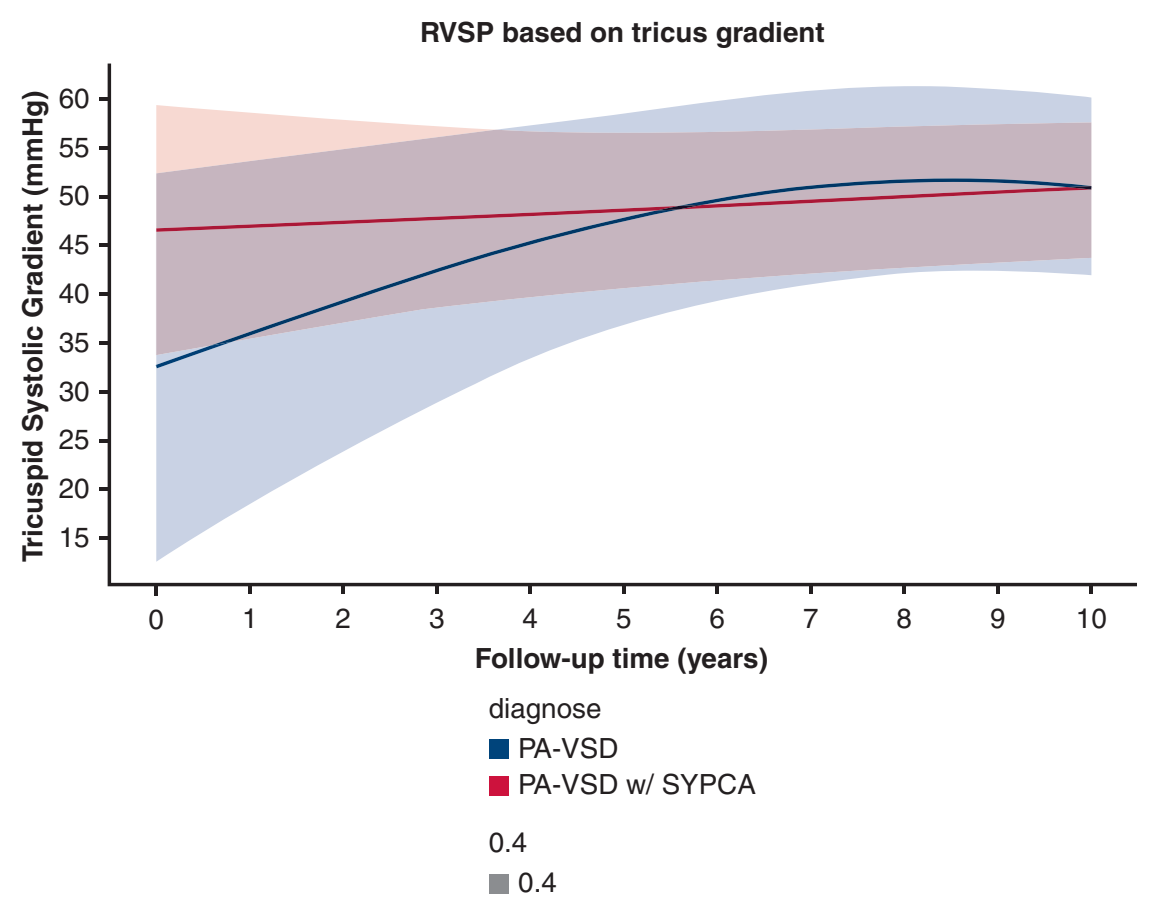

FIGURE 3. Peak right ventricular systolic pressure (RVSP) after correction. PA-VSD, Pulmonary atresia with ventricular septal defect; SYPCA, systemic pulmonary collateral arteries.

indicate stable RV systolic pressure for at least 10 years after correction, while taking into account that $32 \%$ of patients underwent at least 1 catheter intervention on the pulmonary vasculature since correction. Long-term repeated analyses of RV systolic pressure are scarce, but those available generally report stable pressures. ${ }^{15}$ Nonetheless, the extent to which the unifocalized pulmonary vasculature and RV systolic pressure in humans contributes

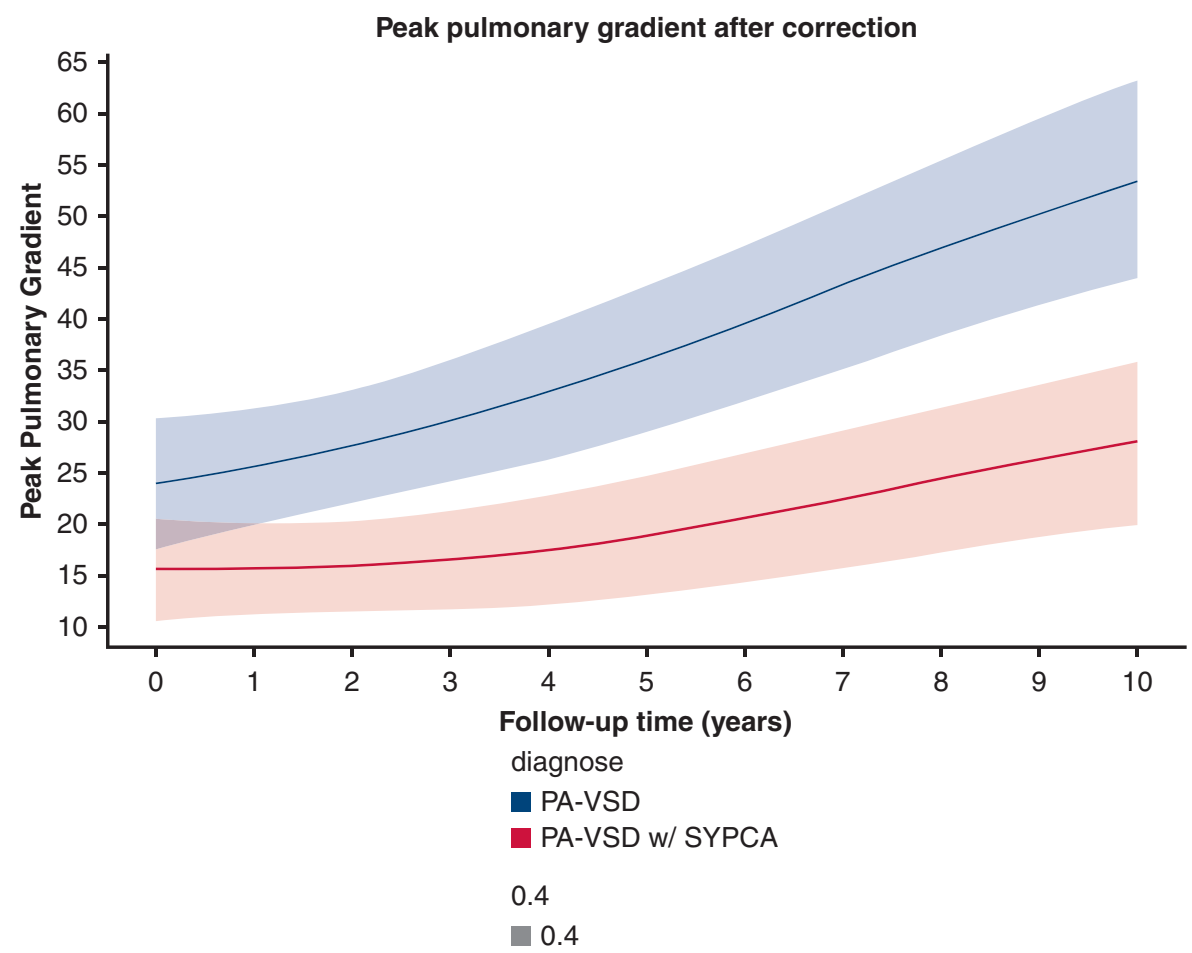

FIGURE 4. Peak pulmonary gradient in homograft recipients. $P A-V S D$, Pulmonary atresia with ventricular septal defect; SYPCA, systemic pulmonary collateral arteries. 


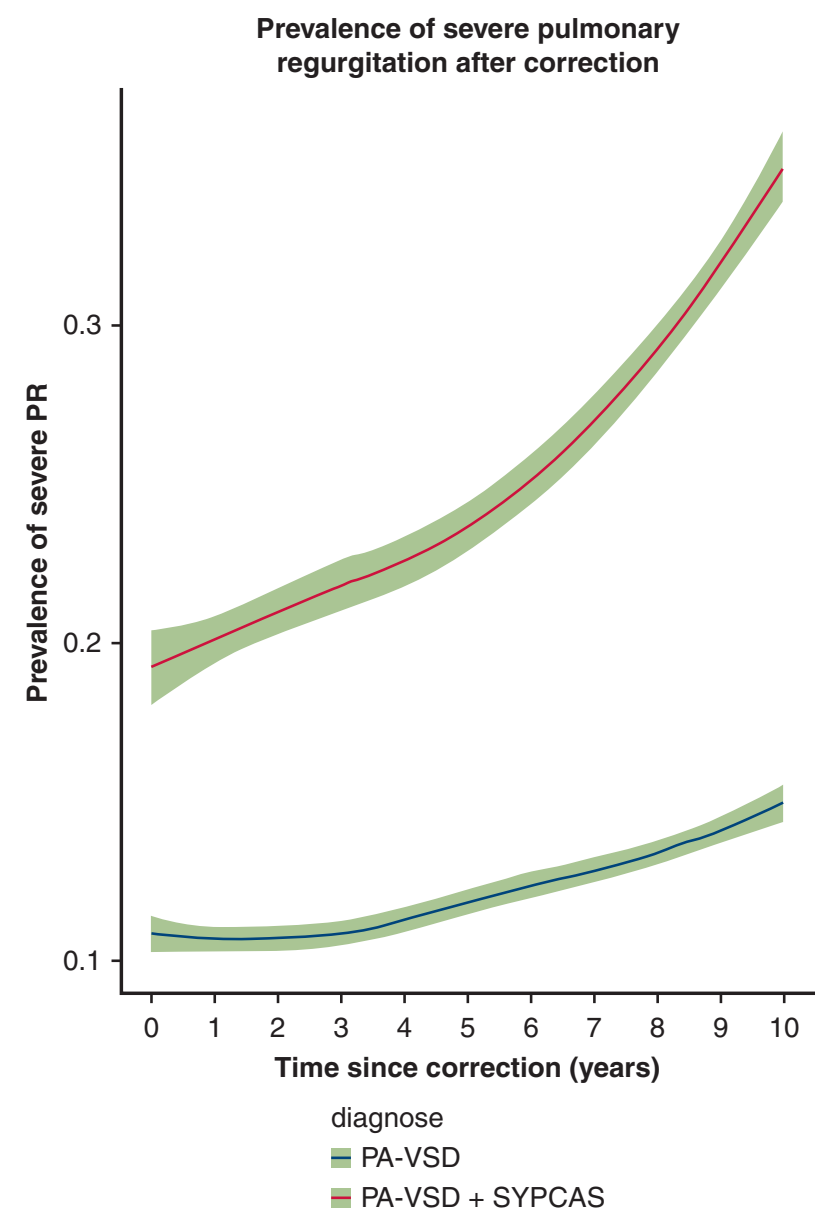

FIGURE 5. Prevalence of severe pulmonary regurgitation $(P R)$ in homograft recipients. $P A-V S D$, Pulmonary atresia with ventricular septal defect; SYPCAS, systemic pulmonary collateral arteries.

to an increased prevalence of severe PR and homograft durability remains uncertain. Our hemodynamic data support the difference in pulmonary artery pressure between the 2 groups. It can be speculated that the higher pressures in patients with SPCAs lead to more regurgitation, and that the homograft degeneration in patients without SPCAs leads to more stenosis in this group.

\section{Surgical Policy}

At both ends of the classification spectrum proposed by Castaneda and colleagues ${ }^{16}$ and the Society of Thoracic Surgeons Congenital Heart Surgery Nomenclature and Database Project, ${ }^{17}$ surgery is relatively straightforward. The surgical approach of patients with pulmonary segments exclusively connected to NPAs is complete correction, sometimes in a single procedure with good short- and long-term results similar to our current findings. ${ }^{15,18}$ Similarly, if systemic collaterals are the sole source of pulmonary blood flow, unifocalization is an essential part of correction. Carrillo and associates ${ }^{19}$ reported acceptable
TABLE 3. Reintervention in hospital survivors after correction

\begin{tabular}{|c|c|c|}
\hline & \multicolumn{2}{|c|}{ Number of events/LOR } \\
\hline & $\begin{array}{c}\text { PA-VSD } \\
\text { with SPCAs } \\
(\mathbf{N}=\mathbf{3 4}) *\end{array}$ & $\begin{array}{c}\text { PA-VSD } \\
\text { without } \\
\text { SPCAs } \\
(\mathbf{N}=\mathbf{2 2})\end{array}$ \\
\hline \multicolumn{3}{|l|}{ Reinterventions $\dagger$} \\
\hline Reintervention per patient, median (range) & $1(0-8)$ & $1(0-3)$ \\
\hline Patients with multiple reinterventions, $\mathrm{n}$ & 10 & 7 \\
\hline Surgical procedures, $\mathrm{n}(\%) \ddagger$ & $22(3.8)$ & $15(3.4)$ \\
\hline PVR & $14(2.4)$ & $12(2.7)$ \\
\hline Plasty confluens/branch PA & $6(1.0)$ & $8(1.8)$ \\
\hline Residual VSD closure & $6(1.0)$ & $4(0.9)$ \\
\hline Transcatheter procedures, $\mathrm{n}(\%) \ddagger$ & $17(2.9)$ & $9(2.0)$ \\
\hline Balloon angioplasty & $15(2.6)$ & $9(2.0)$ \\
\hline With stenting & $13(2.2)$ & $7(1.6)$ \\
\hline Transcatheter PVR & $3(0.5)$ & $2(0.5)$ \\
\hline Pacemaker or ICD placement & $0(0)$ & $0(0)$ \\
\hline \multicolumn{3}{|l|}{ Reinterventions on, $\mathrm{n}(\%) \dagger$} \\
\hline RVOT/MPA, including valve & $20(2.4)$ & $18(4.1)$ \\
\hline Branch PA & $19(3.3)$ & $14(3.2)$ \\
\hline Residual SPCA & $0(0)$ & NA \\
\hline Residual VSD & $6(1.0)$ & $4(0.9)$ \\
\hline Events, n (\%) & & $0(0)$ \\
\hline Late death & $5(0.9)$ & $0(0)$ \\
\hline Noncardiac death & $1(0.2)$ & $0(0)$ \\
\hline Cardiac death & $4(0.7)$ & $0(0)$ \\
\hline Valve-related & $0(0)$ & $0(0)$ \\
\hline SUUD & $4(0.7)$ & $0(0)$ \\
\hline Stroke & $0(0)$ & $0(0)$ \\
\hline TIA & $0(0)$ & $0(0)$ \\
\hline Bleeding & $0(0)$ & $0(0)$ \\
\hline Endocarditis & $2(0.3)$ & $3(0.7)$ \\
\hline
\end{tabular}

$\overline{L O R \text {, Linearized annual occurrence rate since correction; } P A-V S D \text {, pulmonary atresia }}$ with ventricular septal defect; SPCAs, systemic pulmonary collateral arteries; $P V R$, pulmonary valve replacement; $P A$, pulmonary artery; $V S D$, ventricular septal defect; $I C D$, implantable cardioverter defibrillator; RVOT, right ventricular outflow tract; $M P A$, main pulmonary artery; SUUD, sudden unexplained unexpected death; TIA, transient ischemic attack. *Correction was attempted in 37 patients; 1 was unsuccessful, and 2 patients died. $\nmid$ Reinterventions on different anatomic structures during the same session are reported separately. †्†Concomitant procedures are reported separately.

reintervention rates in 28 patients without NPAs who underwent single-stage complete correction. Follow-up was modest, however, and long-term reliability on these SPCAs remains questionable. ${ }^{19}$ The durability of SPCAs in patients with moderately matured NPAs, which probably represent the majority of the population, is unclear. The value of unifocalization in this population has been questioned based on reportedly limited growth capacity and unpredictable durability of SPCAs.,20-22 Our surgical policy is based on staged unifocalization, differing from others, $19,23-25$ in that we do not pursue single-stage unifocalization and correction at the earliest onset, even in cases of complete dual supply of pulmonary blood flow. Our strategy includes combined elements of staged unilateral unifocalization with 


\title{
Homograft durability in patients with Pulmonary atresia and Ventricular Septal Defect
}

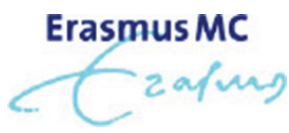

\author{
Methods \\ Comparison of HG durability between patients with PA, VSD with $(n=46)$ and without SPCA's $(n=23)$
}

Results

Freedom from HG replacement was $32 \%$ at 20 years in both groups. Indication was mainly stenosis in patients without SPCA's (89\%) and regurgitation in patients with SPCA's (35\%)

Implications

HG durability in patients with PA and VSD is limited. Carefull follow up is needed with attention for severe regurgitation and stenosis

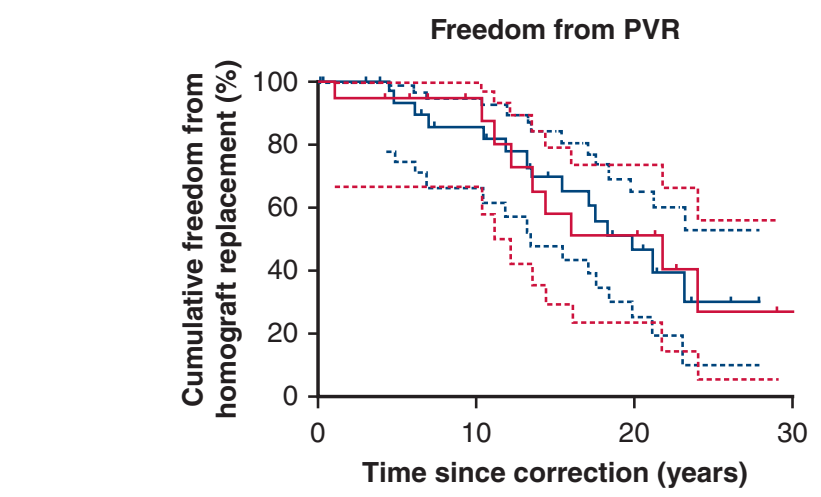

No. at risk:

$\begin{array}{llll}-\mathrm{PA} / \mathrm{VSD}+\mathrm{SPCAs} 33 & 22 & 9 & 0 \\ -\mathrm{PA} / \mathrm{VSD}-\mathrm{SPCAs} 18 & 13 & 7 & 1\end{array}$

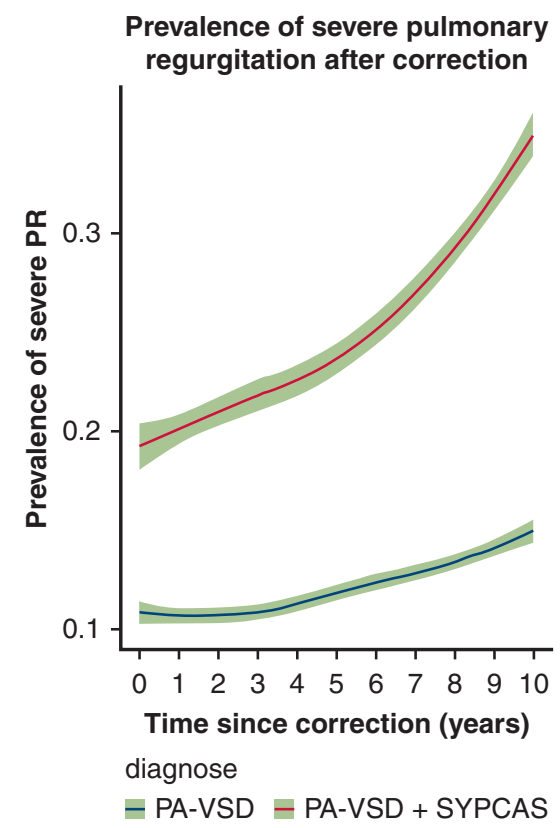

Abbreviations: $H G=$ Homograft, $P A=$ Pulmonary Atersia, $V S D=$ Ventricular Septal Defect, $S P C A$ 's = Systemic-Pulmonary Collateral Arteries

FIGURE 6. Comparison of homograft $(H G)$ durability between patients with pulmonary atresia with ventricular septal defect $(P A-V S D)$ with systemic pulmonary collateral arteries $(S P C A s)(\mathrm{n}=46)$ and without SPCAs $(\mathrm{n}=23)$. Long-term results with freedom from HG replacement of $32 \%$ at 20 years in both groups but with different indications show more stenosis in the group without SPCAs and more regurgitation in the group with SPCAs.

an ipsilateral or central shunt before complete correction, comparable to the policy of the Cleveland Clinic. ${ }^{26}$ However, this approach results in more suture lines in the pulmonary arterial bed and possibly longer exposure of pulmonary arterial segments with increased pulmonary arterial pressure, which may hamper the longevity of homografts used in correction. This effect was not observed in our study, however.

\section{Study Strengths and Limitations}

We have presented the long-term durability of homografts in patients with pulmonary atresia after a uniform strategy of correction with extensive centralized followup. Advanced statistical techniques were used to analyze repeatedly assessed echocardiographic function of homografts and RV systolic pressure. Limitations are inherent to the study's retrospective and single-center nature with a modest patient number, leading to some missing data and the potential for bias.

\section{CONCLUSIONS}

Homograft durability in patients with PA-VSD with or without SPCAs is comparable; however, significant PR is more prevalent in patients with unifocalized SPCAs. A multistage approach with staged unifocalization and concomitant shunting can lead to satisfactory repair rates in patients with PA-VSD and SPCAs. Figure 6 is a graphical abstract with this conclusion.

\section{Conflict of Interest Statement}

The authors reported no conflicts of interest.

The Journal policy requires editors and reviewers to disclose conflicts of interest and to decline handling or reviewing manuscripts for which they may have a conflict 
of interest. The editors and reviewers of this article have no conflicts of interest.

\section{References}

1. Leonard H, Derrick G, O'Sullivan J, Wren C. Natural and unnatural history of pulmonary atresia. Heart. 2000;84:499-503.

2. d'Udekem Y, Alphonso N, Nørgaard MA, Cochrane AD, Grigg LE, Wilkinson JL, et al. Pulmonary atresia with ventricular septal defects and major aortopulmonary collateral arteries: unifocalization brings no long-term benefits. J Thorac Cardiovasc Surg. 2005;130:1496-502.

3. Bauser-Heaton H, Borquez A, Han B, Ladd M, Asija R, Downey L, et al. Programmatic approach to management of tetralogy of Fallot with major aortopulmonary collateral arteries: a 15-year experience with 458 patients. Circ Cardiovasc Interv. 2017; 10:E004952.

4. Carotti A, Albanese SB, Filippelli S, Ravà L, Guccione P, Pongiglione G, et al. Determinants of outcome after surgical treatment of pulmonary atresia with ventricular septal defect and major aortopulmonary collateral arteries. J Thorac Cardiovasc Surg. 2010;140:1092-103.

5. Reddy VM, McElhinney DB, Amin Z, Moore P, Parry AJ, Teitel DF, et al. Early and intermediate outcomes after repair of pulmonary atresia with ventricular septal defect and major aortopulmonary collateral arteries: experience with 85 patients. Circulation. 2000;101:1826-32.

6. Romeo JLR, Mokhles MM, van de Woestijne P, de Jong P, van den Bosch A, van Beynum IM, et al. Long-term clinical outcome and echocardiographic function of homografts in the right ventricular outflow tract. Eur J Cardiothorac Surg. 2019;55:518-26.

7. Mokhles MM, van de Woestijne PC, de Jong PL, Witsenburg M, RoosHesselink JW, Takkenberg JJM, et al. Clinical outcome and health-related quality of life after right ventricular outflow tract reconstruction with an allograft conduit. Eur J Cardiothorac Surg. 2011;40:571-8.

8. Nakata S, Imai Y, Takanashi Y, Kurosawa H, Tezuka K, Nakazawa M, et al. A new method for the quantitative standardization of cross-sectional areas of the pulmonary arteries in congenital heart diseases with decreased pulmonary blood flow. J Thorac Cardiovasc Surg. 1984;88:610-9.

9. Vitanova K, Cleuziou J, Hörer J, Kasnar-Samprec J, Vogt M, Schreiber C, et al. Which type of conduit to choose for right ventricular outflow tract reconstruction in patients below 1 year of age? Eur J Cardiothorac Surg. 2014;46:961-6; discussion 966.

10. Kalfa DM, Loundou A, de Gorce YN, Fraisse A, Metras DR, Macé L, et al. Pulmonary position cryopreserved homograft in non-Ross patients: how to improve the results? Eur J Cardiothorac Surg. 2012;42:981-7.

11. Romeo JLR, Papageorgiou G, van de Woestijne PC, Takkenberg JJM, Westenberg LEH, van Beynum I, et al. Downsized cryopreserved and standard-sized allografts for right ventricular outflow tract reconstruction in children: long-term single-institutional experience. Interact Cardiovasc Thorac Surg. 2018;27:257-63.

12. Bauser-Heaton H, Borquez A, Asija R, Wise-Faberowski L, Zhang Y, Downey L, et al. Pulmonary reinterventions after complete unifocalization and repair in infants and young children with tetralogy of Fallot with major aortopulmonary collaterals. J Thorac Cardiovasc Surg. 2018;155:1696-707.

13. Mainwaring RD, Patrick WL, Punn R, Palmon M, Reddy VM, Hanley FL. Fate of right ventricle to pulmonary artery conduits after complete repair of pulmonary atresia and major aortopulmonary collaterals. Ann Thorac Surg. 2015;99: 1685-91.

14. Petit CJ, Gillespie MJ, Harris MA, Seymour TL, Liu TY, Khan A, et al. Relief of branch pulmonary artery stenosis reduces pulmonary valve insufficiency in a swine model. J Thorac Cardiovasc Surg. 2009;138:382-9.

15. Cho JM, Puga FJ, Danielson GK, Dearani JA, Mair DD, Hagler DJ, et al. Early and long-term results of the surgical treatment of tetralogy of Fallot with pulmonary atresia, with or without major aortopulmonary collateral arteries. J Thorac Cardiovasc Surg. 2002;124:70-81.

16. Castaneda AR, Jonas RA, Mayer JE Jr, Hanley FL. Tetralogy of Fallot. Cardiac Surgery of the Neonate and Infant. Philadelphia: Saunders; 1994:21534.

17. Tchervenkov CI, Roy N. Congenital heart surgery nomenclature and database project: pulmonary atresia-ventricular septal defect. Ann Thorac Surg. 2000; 69(4 Suppl):S97-105.

18. Amark KM, Karamlou T, O'Carroll A, MacDonald C, Freedom RM, Yoo SJ, et al. Independent factors associated with mortality, reintervention, and achievement of complete repair in children with pulmonary atresia with ventricular septal defect. J Am Coll Cardiol. 2006;47:1448-56.

19. Carrillo SA, Mainwaring RD, Patrick WL, Bauser-Heaton HD, Peng L, Reddy VM, et al. Surgical repair of pulmonary atresia with ventricular septal defect and major aortopulmonary collaterals with absent intrapericardial pulmonary arteries. Ann Thorac Surg. 2015;100:606-14.

20. Liava'a M, Brizard CP, Konstantinov IE, Robertson T, Cheung MM, Weintraub R, et al. Pulmonary atresia, ventricular septal defect, and major aortopulmonary collaterals: neonatal pulmonary artery rehabilitation without unifocalization. Ann Thorac Surg. 2012;93:185-91.

21. Brizard CP, Liava'a M, d'Udekem Y. Pulmonary atresia, VSD and MAPCAS: repair without unifocalization. Semin Thorac Cardiovasc Surg Pediatr Card Surg Annu. 2009;139-44.

22. Nørgaard MA, Alphonso N, Cochrane AD, Menahem S, Brizard CP, d'Udekem Y. Major aorto-pulmonary collateral arteries of patients with pulmonary atresia and ventricular septal defect are dilated bronchial arteries. Eur J Cardiothorac Surg. 2006;29:653-8.

23. Tchervenkov CI, Salasidis G, Cecere R, Béland MJ, Jutras L, Paquet M, et al. One-stage midline unifocalization and complete repair in infancy versus multiple-stage unifocalization followed by repair for complex heart disease with major aortopulmonary collaterals. J Thorac Cardiovasc Surg. 1997;114: 727-35; discussion 735-7.

24. Reddy VM, Liddicoat JR, Hanley FL. Midline one-stage complete unifocalization and repair of pulmonary atresia with ventricular septal defect and major aortopulmonary collaterals. J Thorac Cardiovasc Surg. 1995;109:832-44; discussion 844-5.

25. Murthy KS, Rao SG, Naik SK, Coelho R, Krishnan US, Cherian KM. Evolving surgical management for ventricular septal defect, pulmonary atresia, and major aortopulmonary collateral arteries. Ann Thorac Surg. 1999;67:760-4.

26. Duncan BW, Mee RBB, Prieto LR, Rosenthal GL, Mesia CI, Qureshi A, et al. Staged repair of tetralogy of Fallot with pulmonary atresia and major aortopulmonary collateral arteries. J Thorac Cardiovasc Surg. 2003;126:694-702.

Key Words: congenital heart disease, homograft, pulmonary atresia, right ventricular outflow tract reconstruction 
TABLE E1. Linear mixed model design

\begin{tabular}{|c|c|}
\hline Effects & Factors \\
\hline $\begin{array}{l}\text { Fixed } \\
\text { effects }\end{array}$ & $\begin{array}{l}\text { Diagnose (ie, with or without SPCAs) } \\
\text { Sex (ie, male or female) } \\
\text { Age at correction (y) } \\
\text { Type of homograft (aortic or pulmonary) } \\
\text { Weight at correction }(\mathrm{kg}) \\
\text { Length at correction }(\mathrm{cm})\end{array}$ \\
\hline $\begin{array}{l}\text { Random } \\
\text { effects }\end{array}$ & $\begin{array}{l}\text { Time since operation in years } \\
\text { Time since operation in years }{ }^{2} \text { (second-order derivative) } \\
\text { Time since operation in years }{ }^{3} \text { (third-order derivative) }\end{array}$ \\
\hline
\end{tabular}

SPCAs, Systemic pulmonary collateral arteries
TABLE E2. Number of patients at risk and available echocardiography measurements

\begin{tabular}{lcc}
\hline Time, $\mathbf{y}$ & $\begin{array}{c}\text { Number of } \\
\text { patients at risk }\end{array}$ & $\begin{array}{c}\text { Number of } \\
\text { echocardiography } \\
\text { measurements available }\end{array}$ \\
\hline 0 & 51 & 655 \\
\hline 1 & 49 & 608 \\
\hline 2 & 49 & 548 \\
\hline 3 & 49 & 511 \\
\hline 4 & 47 & 456 \\
\hline 5 & 44 & 411 \\
\hline 6 & 43 & 370 \\
\hline 7 & 40 & 338 \\
\hline 8 & 38 & 300 \\
9 & 38 & 273 \\
10 & 37 & 245 \\
\hline
\end{tabular}

